\title{
Studies on ABCD Approach-Based Improvement of Last Mile Delivery in E-Commerce
}

\author{
Huang, Guanwei \\ Tongji University \\ Sino-German School for Postgraduate Studies \\ Shanghai, Yangpu District, Siping Road 1239 \\ guanwei.huang@tongji.edu.cn
}

\author{
Xia, Jie \\ Tongji University \\ Shanghai, Yangpu District, Zhengxiu Road, Nr.19, \\ Building, 501 \\ willdouglas@163.com
}

\begin{abstract}
With the tremendous development of e-commerce in China, the relevant supporting sector, such as logistic industry, is experiencing rapid growth period. However, many problems exposed in the current logistic service, especially in "the last mile delivery", such as low efficiency in first time delivery and difficult to identify the liability of goods damage, etc. These problems prevent the whole industry from sound growing. In this paper, a solution called an ABCD approach was proposed to improve the delivery efficiency and the successful cases were presented to show how this ABCD approach worked. The new delivery approach could improve the delivery successful rate as well the delivery efficiency.
\end{abstract}

Keywords-e-commerce; logistic; last mile delivery; ABCD approach

\section{INTRODUCTION}

E-commerce experienced rapid development in China. According to Ministry of Industry and Information Technology and National Bureau of Statistics of China, the total e-commerce trading volumes in 2012 has reached RMB 8 trillion, and then in 2013, exceeded RMB 10 trillion. In 2014 the number reached RMB 16.39 trillion. In 2015, the trading volumes continued to grow to RMB18.3 trillion, increased $59.4 \%$ compared with the same period of last year. And in the first half of 2016, the trading volumes exceeded RMB 10 trillion.

At present, the "last mile delivery" was carried out in several ways, in addition to delivery to the door of the receiver directly[1]: delivered to convenience stores, property management offices, self-pickup spots and self-pickup cabinets, etc. where the logistic companies have been cooperated with the management[2]. In addition, other new delivery methods like subway and crowdsourcing deliveries are also emerged. All these deliveries showed inherent disadvantages though each of them has been found helpful in certain circumstance. In the "last mile delivery", the most common problems are: too much unsuccessful first time deliveries; and, it is difficult to identify the party or person who should be responsible for the damages[3].

To solve these problems, a new method is proposed in present research to improve delivery efficiency and customer satisfaction.

\section{INTRODUCTION FOR ABCD APPROACH}

The core idea of ABCD(App-Based Communication first, then Delivery)approach is: before the delivery, the end receiver specifies the deliver-to-door time in APP and by this means reducing the failure in last mile delivery. The back end and the user's input of this APP should be managed and manipulated by logistics companies to record and track the whole process of goods distribution. This app should also connect seamlessly with e-commerce trading system and logistics management system. And provides at least following functions: specifying delivery-to-door time, tracking status of orders, tracking the progress of the delivery and evaluating of services etc. In order to remind the end receiver to check the messages, the APP should bind with social APP, such as Wechat or QQ, etc. When the packages are ready to be delivered, a Wechat or QQ message will send to inform end receiver about the arrival of the package. When the packages are received and checked to close the deal, the evaluation and comments on the service can be input in the APP.

The ABCD approach works as follow:

First, divided the normal working hours into serval time periods and mark each period with a check box, e.g. an option for one period. For instance, in general we work 8 hours a day, and a single delivery takes about two hours. So we can provide 4 time periods for the end receiver to choose. For the packages to be delivered, choose those need to be given priority to deliver according existing information. Then asked the end receiver via the App if they can receive the package in the certain period that the App choose for them. If no objection messages received, these packages will be loaded and delivered as per the preset schedule. By replying the App messages, the end receiver can specify the certain period to receive the package. Furthermore, the APP will help the delivering staff to optimize the route for delivery and provide route guide in the App for convenient check. The ABCD process is detailed in Fig. 1. 


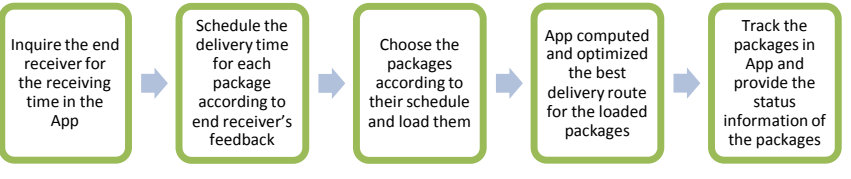

Fig. 1. The process of $A B C D$ approach

In this way, the rate for the successful first time delivery will increase greatly due to the prior communication with end receiver. Even if the end receiver can't accept the package personally, he/she will authorize another person to accept the package instead. Then, he package will be sent to the designated place or person. By utilizing the App as information exchange platform, ABCD approach passes the logistic information to enterprise's information system, so that enterprises can use this information to analyze customer needs to improve working efficiency and customer satisfaction. The information flow of ABCD approach is showed in Fig. 2.
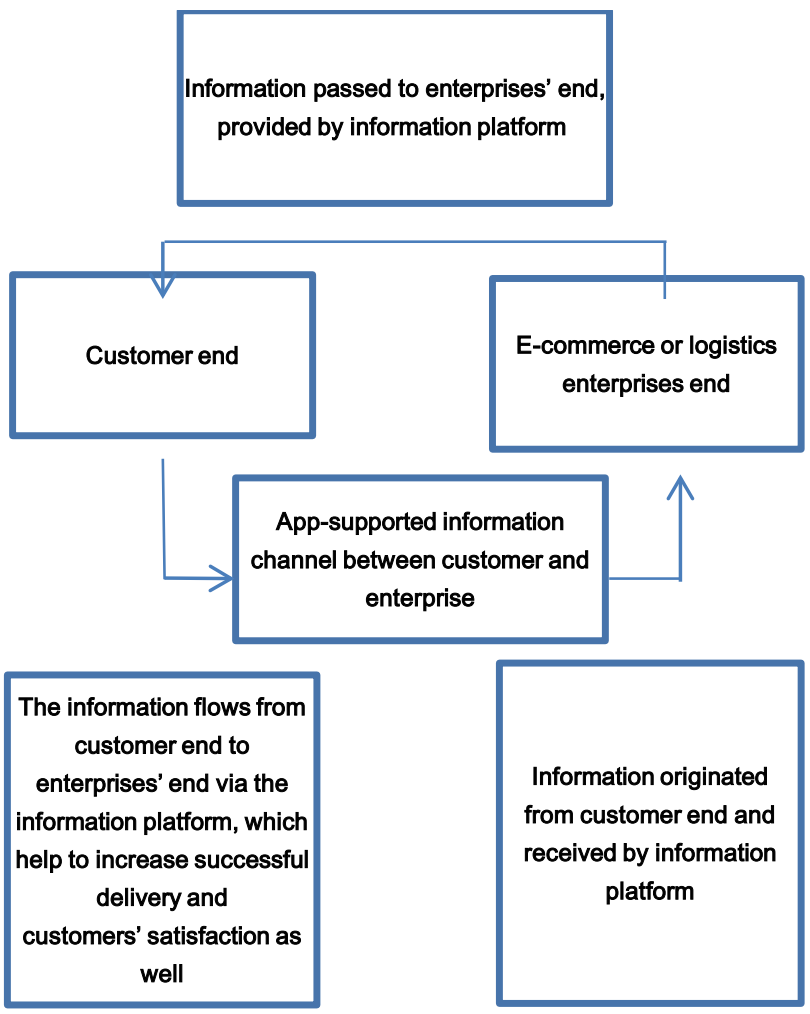

Fig. 2. The information flow of ABCD Approach

The delivery efficiency and successful delivery rate can be greatly improved through ABCD approach and it's easier to identify the party or person who should responsible for the damages. This is because the successful first time delivery increased. For the packages that authorized to be delivered to other person or places, the responsibilities for the damages will be easier identified. In addition, ABCD approach will greatly decrease the communication time between end receivers and delivery staff, the cost on telephone or SM communications can be avoid as well. Table 1 shows the SWOT analysis for ABCD approach.

TABLE I. SWOT ANALYSIS FOR ABCD APPROACH

\begin{tabular}{|c|c|}
\hline $\begin{array}{l}\text { Strength: } \\
\text { 1. It is simply to identify the } \\
\text { responsible of the damage as the } \\
\text { packages are checked by the end } \\
\text { receiver or an authorized person. } \\
2 \text {. The delivery becomes more } \\
\text { transparent and being more } \\
\text { trackable because of the whole } \\
\text { process is recorded in the App. }\end{array}$ & $\begin{array}{l}\text { Weakness: } \\
\text { 1. The development, operation and } \\
\text { maintenance of the App need more } \\
\text { investments, this increase the cost } \\
\text { of logistics enterprises'. }\end{array}$ \\
\hline $\begin{array}{l}\text { Opportunity: } \\
\text { 1. The evaluation system of the APP } \\
\text { can effectively improve the service } \\
\text { quality for the last mile delivery and } \\
\text { thus increase the customer } \\
\text { satisfaction. } \\
\text { 2. Eliminated the telephone } \\
\text { communication, the cost on } \\
\text { telephone and SM is avoided. }\end{array}$ & $\begin{array}{l}\text { Threaten: } \\
\text { 1. The new APP may need a long } \\
\text { time to be accepted by the public, } \\
\text { its promotion needs both time and } \\
\text { money. }\end{array}$ \\
\hline
\end{tabular}

\section{THE ANALYSIS OF DELIVERY MODEL BASED ON ABCD APPROACH}

ABCD approach based delivery improves logistic efficiency in three ways: increase the successful delivery; reduce the communication time; optimize the space in vehicle.

\section{A. Increase the successful delivery}

In current delivery models, the delivery staff will collect the packages which targeted to his area of responsibility and load them to his delivery vehicle by him, then deliver to the receivers. Because the end receiver does not know the delivery schedule of the package, the packages may not be accepted then they are delivered to the door of the end receivers. The unsuccessful delivery will not only waste the working time of delivery staff's, but occupy the vehicle space, so that the total number of delivered packages will be compromised. By using ABCD approach, before the packages are loaded, a sound communication with the end receiver will be done through the APP, ensuring the every loaded package can be accepted. Theoretically, the successful delivery rate can reach $100 \%$. However, due to the reasons of receiver's side, a few packages may not be accepted in actual delivery. But compared with current delivery models, ABCD approach holds greater advantage.

\section{B. Reduce the communication time}

In traditional delivery models, the delivery staff will call or text the end receiver when he/she is going to arrive at the delivery destination. A survey carried out in logistics and distribution enterprises showed that, this kind of communication takes almost a half working time of the delivery staff and decrease the working efficiency greatly. By using ABCD approach, such communication can be done with APP, the delivery staff will have more time to delivery more packages, increasing the working efficiency. 


\section{Optimize the space in vehicle}

At present, about 50-100 packages can be loaded into the delivery vehicle, motor wagon in general. The unaccepted packages will occupy the space in the delivery vehicle, compromising the load rate. In addition, the unaccepted packages must be delivered again in a different time period, further decease the delivery efficiency. By using ABCD approach, the unaccepted packages will be loaded because of the prior communication; only the acceptable packages will be loaded. With the total amount of loading space unchanged, vehicle space is used more efficiently. The efficiency for the overall delivery is improved.

\section{THE EFFECTIVENESS ANALYSIS OF ABCD APPROACH}

Theoretically, the effectiveness of ABCD approach can be verified in two ways: the number of accepted packages per day and accepted rate in specified time period.

\section{A. The number of accepted packages per day \\ Each factor is defined as following table 2:}

TABLE II. DEFINITION OF FACTORS OF THE NUMBER OF ACCEPTED PACKAGES PER DAY

\begin{tabular}{|l|l|}
\hline $\begin{array}{l}\text { The number of accepted packages } \\
\text { per day }\end{array}$ & $\mathrm{P}$ \\
\hline Total working time per day & $\mathrm{Z}$ \\
\hline Single delivery time & $\mathrm{T}$ \\
\hline Daily delivery times & $\mathrm{k}, k=\frac{Z}{t}$ \\
\hline $\begin{array}{l}\text { Number of accepted packages in } \\
\text { one single delivery }\end{array}$ & $\mathrm{q}$ \\
\hline $\begin{array}{l}\text { Number of accepted packages in } \\
\text { one day }\end{array}$ & $P=q^{*} k=q^{*} \frac{Z}{T}$ \\
\hline
\end{tabular}

To increase the number of accepted packages in one day, with total working time $\mathrm{N}$ unchanged, the only thing we can do is increase $\mathrm{q}$ or decease $\mathrm{T}$. According to the previous analysis, compared with the current delivery models, ABCD approach will bring a higher $\mathrm{q}$ and a lower $\mathrm{T}$, which leads to the increase of P, e.g. with ABCD approach, the daily accepted packages will increase.

\section{B. Accepted rate in specified time period}

Each factor is defined as following table 3:
TABLE III. DEFINITION OF FACTORS OF THE ACCEPTED RATE IN SPECIFIED TIME PERIOD:

\begin{tabular}{|l|l|}
\hline $\begin{array}{l}\text { Accepted rate in specified time } \\
\text { period }\end{array}$ & $\mathrm{M}$ \\
\hline Single delivery time & $\mathrm{T}$ \\
\hline $\begin{array}{l}\text { Number of accepted packages in } \\
\text { one single delivery }\end{array}$ & $\mathrm{q}$ \\
\hline $\begin{array}{l}\text { Accepted rate in specified time } \\
\text { period }\end{array}$ & $M=\frac{q}{T}$ \\
\hline $\begin{array}{l}\text { Accepted rate in specified time } \\
\text { period }\end{array}$ & $\mathrm{M}$ \\
\hline Single delivery time & $\mathrm{T}$ \\
\hline $\begin{array}{l}\text { Number of accepted packages in } \\
\text { one single delivery }\end{array}$ & $\mathrm{q}$ \\
\hline $\begin{array}{l}\text { Accepted rate in specified time } \\
\text { period }\end{array}$ & $M=\frac{q}{T}$ \\
\hline
\end{tabular}

To improve the accepted rate in specified time period $\mathrm{M}$, we need to increase $\mathrm{q}$ or decrease $\mathrm{T}$. According to the previous analysis, compared with the current delivery models, ABCD approach will bring a higher $\mathrm{q}$ and a lower $\mathrm{T}$, which leads to the increase of $\mathrm{M}$, e.g. with ABCD approach, the accepted rate in specified time period will increase.

The conclusion above will be verified with actual data. According to a field survey in Shanghai, the following data regards to the last mile delivery was gained: take certain distribution office as a center point to draw a circle with radius of two or three kilometers. Within this circle, is the area of responsibility of this distribution office. One delivery staff can load sixty packages in a single delivery. A complete delivery (leaving the delivery office with fully loaded vehicle and return with all packages delivered) takes about two hours. During these two hours, the delivery staff needs: 0.6 hour to drive, 0.1 hour to wait for traffic congestion to be resolved, 1.3 hours to contact end receiver and deliver the packages to doors. On average, fifty packages are accepted in each delivery. The total working hour in a day is eight hours.

From the data above we know:

Single delivery time $\mathrm{t}=$ drive $(\mathrm{t} 1)+$ congestion(t2)+ contacting and delivery to door (t3)

The mathematical expression is: $T=t_{1}+t_{2}+t_{3}$, where $t_{1}=0.6$ (hour),$t_{2}=0.1$ (hour),$t_{3}=1.3$ (hour),$T=2$ (hour)

(1)As to the number of accepted packages in one day, we use the indicator $P=q^{*} k=q^{*} \frac{Z}{T}$ to evaluate it.

Compared with current delivery models, ABCD approach eliminates the contacting time, so

$$
T_{2}=t_{1}+t_{2}=0.7+0.2=0.9 \text { (hour) }
$$

Besides, because of the prior communication with end receivers, we assume that all the packages are accepted, so $q_{2}=60$

The calculation of two delivery models shown as table 4 below: 
TABLE IV. CALCULATION OF TWO DELIVERY MODELS WITH THE INDICATOR OF P :

\begin{tabular}{|c|c|c|}
\hline & Current delivery models & ABCD Approach \\
\hline $\begin{array}{l}\text { Number of } \\
\text { accepted } \\
\text { packages in one } \\
\text { single delivery } \\
\text { (q) }\end{array}$ & $q_{1}=50$ & $q_{2}=60$ \\
\hline $\begin{array}{l}\text { Total working } \\
\text { time a day }\end{array}$ & $Z_{1}=8$ (hour $)$ & $Z_{2}=8$ (hour $)$ \\
\hline $\begin{array}{l}\text { Single delivery } \\
\text { time }\end{array}$ & $\begin{array}{l}T_{1}=T \\
=t_{1}+t_{2}+t_{3} \\
=2(\text { hour })\end{array}$ & $\begin{array}{l}T_{2}=t_{1}+t_{2} \\
=0.7+0.2 \\
=0.9(\text { hour })\end{array}$ \\
\hline $\begin{array}{l}\text { Number of } \\
\text { accepted } \\
\text { packages in one } \\
\text { day (P) }\end{array}$ & $\begin{array}{l}P_{1}=q_{1} * k_{1} \\
=q_{1} * \frac{Z_{1}}{T}= \\
50 * 4 \\
=200 \text { (packages) }\end{array}$ & $\begin{array}{l}P_{2}=q_{2} * k_{2} \\
=q_{2} * \frac{Z_{2}}{T} \\
=60 * \frac{8}{0.9} \\
=533 \text { (packages) }\end{array}$ \\
\hline
\end{tabular}

From the calculation above, we can see that: compared with the current delivery models, ABCD approach can greatly increase the number of accepted packages in one day. Each deliver staff can deliver 2.67 times amount of packages than before

(2) As to the accepted rate in specified time period, we use the indicator $\mathrm{M}$ to evaluate it.

Because of prior communication with end receivers, we assume that all the packages are accepted, so

$$
q_{2}=60
$$
SO

Besides, the time spent on contact the end receivers is avoid,

$$
T_{2}=t_{1}+t_{2}=0.7+0.2=0.9 \text { (hour) }
$$
below:

The calculation of two delivery models shown as table 5

TABLE V. CALCULATION OF TWO DELIVERY MODELS WITH THE INDICATOR OF M:

\begin{tabular}{|l|l|l|}
\hline $\begin{array}{l}\text { Number of accepted } \\
\text { packages in one single } \\
\text { delivery (q) }\end{array}$ & Current delivery models & ABCD Approach \\
\hline Single delivery time (T) & $\begin{array}{l}q_{1}=T \\
=t_{1}+t_{2}+t_{3} \\
=2(\text { hour })\end{array}$ & $\begin{array}{l}T_{2}=t_{1}+t_{2} \\
=0.7+0.2 \\
=0.9(\text { hour })\end{array}$ \\
\hline $\begin{array}{l}\text { Accepted rate in specified } \\
\text { time period (M) }\end{array}$ & $\begin{array}{l}M_{1}=\frac{q_{1}}{T_{1}} \\
=\frac{50}{2}\end{array}$ & $\begin{array}{l}M_{2}=\frac{q_{2}}{T_{2}} \\
60\end{array}$ \\
$=25$ & $\begin{array}{l}0.9 \\
=66.67 \\
(\text { packages / hour })\end{array}$ \\
\hline
\end{tabular}

Compared with current delivery models, ABCD approach improves the Accepted rate in specified time period greatly. Each deliver staff can deliver 2.67 times amount of packages than before.

From the calculation above, we can see that during the same working hours, ABCD approach can increase the amount of accepted packages and enhance working efficiency greatly. By using ABCD approach, logistic/express enterprises can accelerate the business circle by eliminating the time-wasting communication and increasing the accepted packages, thus the working efficiency got improved and the cost of operation can be reduced. Besides, the prior communication with end receivers helps the enterprises to deliver a customer-oriented service which would in enhance the competitiveness of enterprises' directly.

\section{CONCLUSION}

The last mile delivery in e-commerce is the only stage where the end clients would be contacted with directly[4]. Featured with large amount of work to do and higher cost in operation, this stage becomes one of the very important influential factors in the development of e-commerce[5]. The ABCD approach proposed in this paper will be great help in improving logistic delivery working efficiency, as well reducing the delivery cost of the closing end of logistic operation. Furthermore, ABCD approach also helps to enhance the customer satisfaction.

\section{REFERENCES}

[1] Haul Lee.The Last Mile Bottleneck[J].Logtistics \& Transport Focus, 2000, 2 (7):8

[2] Moreno Muffatto*, Andrea Payaro. Implementation of e-procurement and e-fulfillment processes:A comparison of cases in the motorcycle industry[J]. Production Economics 89 (2004) 339-351

[3] David Simchi-Levi, Edith Simchi-Levi. The effect of e-buiness on supply chain stragtegy[C]. ESD Internal Symposium(2003)

[4] Kent N. Gourdin.Global logistics management: a competitive advantage for the new millennium [M]. Wiley-Blackwell,2001

[5] Deckmyn. D.Transport Company Dives Into Fish Market [J]. Computerworld, 1999, 29 (33): 20-21 